\title{
Editorial \\ A Presidential Blueprint for Success and Change
}

\author{
Frederick L. Greene, MD \\ Department of Surgery, Carolinas Medical Center, Charlotte, NC, USA
}

When the senior editors of our journal asked me to write an editorial as a companion piece to Dr. Nicholas Petrelli's Society of Surgical Oncology (SSO) presidential address entitled "I'm in a New York State of Mind", ${ }^{1}$ I was honored and delighted, but frankly incredulous. For those of us who attended the Society of Surgical Oncology Cancer Symposium in March 2008 in Chicago and were fortunate to have heard Nick's presentation, to my mind there was no way that the publication of the address could convey the humor, pathos, exuberance, and bluster that emanated from that oration. In addition, no commentary could ever do justice to a well-presented and carefully scripted presidential address - and frankly that is why most representations of this genre rarely are fodder for editorial comment.

This presidential address, however, is different - it really contains a strong message and outlines a plan. If I accomplish nothing else in this commentary, I hope that you - those who heard the oral presentation and those who did not - will share my excitement regarding Dr. Petrelli's message, turn a few pages to the published manuscript and take the time to understand the power, commitment, and superb outcome that a visionary leader working with a good team can accomplish in creating a metamorphosis of both a community-based health care center and the entire cancer care culture in the state of Delaware.

Dr. Petrelli and his colleagues, working with support from the National Cancer Institute (NCI), have attacked the critical problem of cancer in their state and, embracing the power of their community/

Published online July 15, 2008.

Address correspondence and reprint requests to: Frederick L. Greene, MD; E-mail: frederick.greene@carolinashealthcare.org

Published by Springer Science+Business Media, LLC @ 2008 The Society of Surgical Oncology, Inc. academic teaching center and its dedicated staff, have transformed the mindset of the community. In addition, they have played a key role in partnering with a state government dedicated to reducing the suffering from cancer within Delaware's borders. Through hard work and using a blueprint that utilizes the excellence in clinical cancer care demonstrated by community oncologists from all disciplines, Dr. Petrelli and colleagues were successful in their application to the NCI Community Cancer Center Program (NCCCP). The initial group of 14 community cancer centers was chosen for their commitment to clinical trials, transitional research, outstanding data collection, and a goal to reduce healthcare disparities in their community. While barely 1 year into this NCI designation, the group at the Helen F. Graham Cancer Center has achieved $20 \%$ accrual to NCI-group trials and will no doubt reach their goal of $30 \%$. Since accrual to adult trials in cancer is generally below $5 \%$, the outstanding commitment to reach these benchmarks is selfevident.

All of us who are dedicated to realizing excellence in cancer care through the power of our community hospital cancer programs will gain much insight from reviewing Dr. Petrelli's blueprint. In my role as chairman of the Commission on Cancer of the American College of Surgeons, I am particularly heartened to see the heights that a strong community cancer program can achieve. Dr. Petrelli and his colleagues at the Graham Cancer Center have thrown down the gauntlet, challenging the majority of the 1,480 facilities recognized by the Commission on Cancer Approvals Program which are labeled community hospitals. The achievements of our Delaware colleagues can be repeated at our community healthcare facilities if we adhere carefully to their published blueprint. 
Yes, Nick, you have enlightened us, humored us, thanked us, and entertained us through your memorable presidential address. More importantly, you have challenged each one of us to achieve the same level of cancer care that you and your team have realized. You have also challenged your journal: yes, we will make a firm commitment to recognize the outstanding scientific and outcomes-related submissions created by dedicated surgical oncologists working in the community setting.

\section{REFERENCE}

1. Petrelli NJ. I'm in a New York state of mind. Ann Surg Oncol 15: 2008. DOI: 10.1245/s10434-008-9937-7. 